\title{
O PERCURSO HISTÓRICO EM TORNO DAS NOVAS DIRETRIZES E NORMAS NACIONAIS PARA A OFERTA DE CURSOS DE EDUCAÇÃO SUPERIOR NA MODALIDADE EaD.
}

\author{
Rafaela Bohrz - Universidade de Passo Fundo (UPF) - rafabohrz@ yahoo.com.br Jane \\ Kelly de Freitas Santos - Universidade de Passo Fundo (UPF), Bolsista CAPES - \\ janekellyfreitas@yahoo.com.br
}

\begin{abstract}
RESUMO
Este artigo apresenta reflexões acerca do debate sobre as Diretrizes e Normas Nacionais para a oferta de Programas e Cursos de Educação Superior na Modalidade a Distância. Inicialmente efetuou-se um estudo sobre o documento "Referenciais de Qualidade para Educação Superior a distância" e a análise da audiência pública interativa, transmitida via Youtube, promovida pela TV Senado no final de 2015. Posteriormente, tendo em vista que as legislações vigentes norteiam esta modalidade, reforçam e legitimam os debates na área, utilizou-se da metodologia de pesquisa documental para a averiguação dos dados obtidos. Por último, foi feita uma verificação da Resolução ${ }^{\circ}{ }^{1}$, de 2016 , em relação ao atendimento dos pressupostos iniciais sugeridos no marco regulatório. Estes estudos objetivam refletir se as dimensões presentes nos documentos analisados foram abordadas na audiência pública interativa e verificar se as proposições sugeridas na elaboração do documento foram abordadas nas novas diretrizes e se apresentam avanços significativos ao atual contexto da EaD. As conclusões permeiam as conjecturas de que é necessário reconhecer que este novo documento levanta questões pedagógicas e gerenciais que merecem revisões para melhorar o Ensino a Distância no país.
\end{abstract}

Palavras-chave: Educação a Distância. Legislações. Ensino Superior.

\section{THE HISTORICAL JOURNEY AROUND THE NEW NATIONAL GUIDELINES AND STANDARDS FOR THE OFFER PROGRAMS AND HIGHER EDUCATION COURSES IN THE DISTANCE LEARNING MODALITY.}

\begin{abstract}
This article presents reflections about the debate about the national guidelines and standards for the offer programs and higher education courses in the Distance Learning modality. Initially, was realized a study about the "Distance Learning quality education benchmarks" document and the analysis of interactive public hearing, broadcasted through Youtube, promoted by Senate TV at the end of 2015. Afterwards, considering that the current legislations guide this modality, strengthen and legitimize the debates in the area, was used the documentary research methodology to investigation of data obtained. Finally, was made a verification of resolution number 1, of 2016, in relation to compliance with the initial assumptions proposed in regulatory framework. These studies have as aim to reflect if the dimensions involved in the documents that were studied, were mentioned in interactive public hearing and check if the suggested
\end{abstract}


propositions in the elaboration of the document were approached in the news guidelines and if it presents significant advances to Distance Learning modern context. Conclusions suggested suppositions which is necessary to recognize that this new document raises pedagogical and managerial questions, that deserve reviews to improve Distance Learning in the country.

Keywords: Distance Learning, Legislation, Higher Education

\section{INTRODUÇÃO}

No contexto da Educação a Distância, os estudos das legislações vigentes norteiam, reforçam e legitimam os debates na área, visto que os instrumentos disponíveis definem os princípios, diretrizes, critérios e regulamentam essa modalidade, fundamentando, assim, sua importância perante o atual cenário educacional.

Frente a isso, o novo Marco Regulatório para a EaD (2015) caracterizou-se como um documento inicial, elaborado pelo Conselho Nacional de Educação, que apontou um esboço para as novas diretrizes no que diz respeito à oferta de cursos e programas para a modalidade. Embora sua aprovação venha sendo discutida há anos, o CNE, através da Câmara de Educação Superior, aprovou no dia 10 de dezembro, o Parecer $n^{\circ} 564$, de 2015, que propõe as Diretrizes e Normas Nacionais para a oferta de Programas e Cursos de Educação Superior na Modalidade a Distância, sendo instituído posteriormente pela Resolução no 1 , de 11 de março de 2016.

Com o objetivo de dialogar com esta temática, a comissão designada para discutir o novo Marco Regulatório realizou ao longo dos anos uma ampla discussão com os diferentes setores, através de debates, que envolveram os setores públicos e privados. Logo, a audiência virtual realizada em 15 de outubro de 2015, e transmitida virtualmente, via canal da TV Senado no Youtube, objetivou deliberar sobre as propostas feitas para a modalidade a distância.

Ao discutir tais propostas e apontar novas diretrizes para a oferta de cursos e programas de Educação a Distância, diferentes proposições dessa modalidade foram argumentadas. Nesse contexto, esta investigação busca responder à seguinte questãoproblema: as recomendações sugeridas ao longo da elaboração do marco regulatório estão explícitas nas novas diretrizes, logo, essas normas sugerem avanços significativos a $\mathrm{EaD}$ ?

Por fim, a partir das questões de investigação propostas, este estudo objetiva: a) traçar um paralelo, refletir e investigar se as dimensões presentes nos documentos analisados foram abordadas na audiência pública interativa, promovida pela TV Senado e b) verificar se as proposições sugeridas na elaboração do documento foram abordadas nas novas diretrizes e se apresentam avanços significativos ao atual contexto da EaD.

\section{EMBASAMENTO TEÓRICO}

A fim de que um curso à distância atinja seus objetivos com qualidade e equidade, muitos requisitos referentes aos aspectos pedagógicos, recursos humanos e infraestrutura precisam ser observados de forma criteriosa.

Desse modo, tendo em vista que a pesquisa documental, de acordo com Prodanov e Freitas (2013, p.55): "baseia-se em materiais que não receberam ainda um 
tratamento analítico ou que podem ser reelaborados de acordo com os objetivos da pesquisa" fez-se necessário a verificação da contemplação dos tópicos presentes nos Referenciais de Qualidade para Educação Superior a distância em relação às proposições sugeridas na audiência virtual. Neste documento legislativo do MEC, é possível identificar a presença de oito tópicos que buscam atender às dimensões pedagógicas, recursos humanos e infraestrutura. Tais elementos referem-se aos processos específicos de regulação, supervisão e avaliação da modalidade a distância e como citado no próprio material, BRASIL (2007, p.8) "não são entidades isoladas, se interpenetram e se desdobram em outros subtópicos", logo percebe-se que as sugestões dadas pelos representantes das entidades foram além daquilo já sugerido no documento norteador, uma vez que as mesmas objetivam organizar os sistemas de EaD.

Nesse sentido, de modo a orientar as iniciativas de Educação a Distância e qualificar os procedimentos, foi elaborado os "Referenciais de Qualidade para a Educação Superior à Distância". Proposto pelo MEC, inicialmente em 1998, tal documento tem como objetivo definir princípios, diretrizes e critérios para as instituições que oferecem cursos nesta modalidade. Atualizado constantemente, em 2003 e, na última versão, em junho de 2007, teve suas mudanças implementadas devido ao amadurecimento do processo, a inserção e o uso das Tecnologias de Informação e da Comunicação. Além disso, ele é norteado pelos tópicos a seguir.

O primeiro, (i) Concepção de educação e currículo no processo de ensino e aprendizagem, faz o delineamento do processo de ensino e aprendizagem, bem como, de acordo com o BRASIL (2007, p.8) norteia: "toda a proposta de organização do currículo e seu desenvolvimento", sempre de acordo com o projeto político pedagógico. A interdisciplinaridade e a contextualização devem ser previstas nos currículos de cursos a distância, vinculando-se ao uso das tecnologias. O segundo tópico, (ii) Sistemas de Comunicação, trata do princípio da interação e da interatividade, os quais devem, de acordo com BRASIL (2007, p.10): "ser garantidos no uso de qualquer meio tecnológico a ser disponibilizado" e compartilhados entre os diferentes sujeitos envolvidos na modalidade $\mathrm{EaD}$, sejam eles de forma online - via ambiente virtual de aprendizagem - ou presencial - nos polos de apoio presencial. No próximo ponto, (iii) Material didático, percebe-se que o mesmo, segundo BRASIL (2007, p.13) "deve estar concebido de acordo com os princípios epistemológicos, metodológicos e políticos explicitados no projeto pedagógico" e deve integrar diferentes mídias, assegurando a interação entre os agentes do processo educacional.

Além dos tópicos supracitados, o item (iv) Avaliação contempla o processo de aprendizagem, presencial nos polos de apoio, e à avaliação institucional, a qual necessita mensurar a organização didático-pedagógica, o corpo docente e de tutores, a classe técnica-administrativa, os discentes e as instalações físicas. Em seguida, no tópico (v) Equipe multidisciplinar, o enfoque está na equipe multidisciplinar, formada por docentes, tutores, presenciais e a distância, e técnicos administrativos que, conforme BRASIL (2007, p.19): "devem estar em constante qualificação, são essenciais para uma oferta de qualidade". No próximo, (vi) Infraestrutura de apoio; aborda-se a infraestrutura material, equipamentos audiovisuais, e a infraestrutura física da sede da IES e dos polos de apoio presenciais.

No sétimo tópico, Gestão Acadêmico-Administrativa contempla-se a gestão integrada aos demais processos da instituição e, por fim, em (viii) Sustentabilidade 
financeira aponta-se a necessidade de planejamento da IES em conformidade com as propostas pedagógicas.

Percebe-se, portanto, que tais orientações contidas nos oito tópicos possuem função indutora e auxiliam na definição dos princípios, diretrizes e critérios para as instituições que oferecem cursos nesta modalidade, bem como, na organização do sistema de Educação a Distância no país.

\section{METODOLOGIA DO TRABALHO}

Com o objetivo de obter maior qualidade no estudo, optou-se pelo uso da pesquisa documental. Para compreender o que este tipo de pesquisa e como se constitui sua análise, Sá-Silva, Almeida e Guindani (2009, p.2) nos orientam e dão pressupostos necessários, propondo algumas perguntas norteadoras que dão suporte para $\mathrm{o}$ entendimento acerca desta categoria. As questões apontadas são: "O que é a pesquisa documental? O que é um documento? Como se constitui uma análise documental?"

Os autores supracitados demonstram que a realização de uma pesquisa documental vai além do simples fazer, pois a mesma deve compreender epistemologicamente o sentido dos estudos em educação, mais especificamente, esse tipo de técnica é um dos passos para a realização de um trabalho que promova a validação de boas pesquisas.

Em vista disso foram analisados os aspectos pedagógicos, recursos humanos e infraestrutura, dispostos no documento "Referenciais de Qualidade para Educação Superior a distância", no viés da audiência pública interativa, que objetivou debater o novo marco regulatório, as novas diretrizes e normas nacionais para a oferta de programas e cursos de Educação Superior na modalidade EaD.

A análise dos dados obtidos se deu por meio das falas e propostas dos debatedores presentes na audiência virtual. Estas informações foram confrontadas através do aporte investigativo levantado no embasamento teórico e permitiram a identificação dos resultados a seguir.

\section{ANÁLISE DOS DADOS}

Em 15 de outubro de 2015, a Comissão de Educação, Cultura e Esporte (CE) realizou e transmitiu virtualmente, via canal da TV Senado no Youtube, uma audiência pública interativa $^{1}$, que objetivou debater o novo marco regulatório da Educação a Distância, o qual posteriormente originou, em março de 2016, as Diretrizes e Normas Nacionais para a oferta de Programas e Cursos de Educação Superior na Modalidade a Distância. Tal discussão pode contribuir para a reflexão sobre algumas das oito dimensões propostas no documento orientativo do MEC, conforme pode ser observado abaixo.

\subsection{Concepção de educação e currículo no processo de ensino e aprendizagem}

Ao analisar esta variável, verificou-se por meio da fala diretora da Associação Brasileira das Mantenedoras de Ensino Superior (ABMES), Gislaine Moreno, uma

\footnotetext{
${ }^{1}$ Disponível em: <https://www.youtube.com/watch?v=ZFBL5tOFZEU\&feature=youtu.be>.
} 
preocupação quanto ao tratamento do projeto político pedagógico e com as ações dispostas no Plano de Desenvolvimento Institucional das instituições de Ensino Superior, sendo assim, coerente com o que se propõe no documento do MEC.

\subsection{Equipe multidisciplinar}

Nesta dimensão, identificou-se por parte de Nara Pimentel, membro do Comitê de Coordenação Política da Associação Universidade em Rede e de José Roberto Covac, diretor jurídico do sindicato das Mantenedoras de Ensino Superior uma grande preocupação quanto a tutoria nesta modalidade educacional, principalmente no que se refere à valorização do tutor e a necessidade de adequação da categoria na Consolidação das Leis do Trabalho.

\subsection{Infraestrutura de apoio}

No tópico infraestrutura de apoio averiguou-se uma apreensão de diferentes debatedores, tendo em vista a questão dos polos de apoio presencial e a distância. $\mathrm{O}$ diretor da Associação Brasileira de Educação a Distância, Luciano Sathler Rosa Guimarães, Gislaine Moreno (ABMES) e João Paulo Bachur, diretor da Política Regulatória da Secretaria de Regulação e Supervisão da Educação Superior do Ministério da Educação sugerem a criação de mais polos presenciais; a necessidade de maior responsabilidade social e a conexão dos polos com as regiões em que estão instalados; a revisão dos projetos de desenvolvimento de polos de apoio presenciais, em busca da promoção da expansão universitária; e a inovação na disponibilização de bibliotecas e laboratórios virtuais aos discentes.

\section{DISCUSSÃO DOS DADOS}

De um modo geral, percebeu-se que a audiência virtual abordou, de forma mais direta, apenas três dimensões presentes nos "Referenciais de Qualidade para Educação Superior a distância". As demais sugestões propostas pelos debatedores envolveram temáticas relacionadas à necessidade de (a): expansão da número de matrículas no Ensino Superior, o que pode ser efetuado através da EaD; atualização do Decreto $\mathrm{n}^{\mathbf{0}}$ 5.622, de 19 de dezembro de 2005, que estabelece as diretrizes e bases da educação nacional; da Portaria normativa $\mathrm{n}^{\circ}$ 40, de 12 de dezembro de 2007 que institui o e-MEC, sistema eletrônico de fluxo de trabalho e gerenciamento de informações relativas aos processos de regulação da educação superior no sistema federal de educação e, ainda, da Lei $\mathrm{n}^{\circ}$ 9.394, de 20 de dezembro de 1996, que estabelece as diretrizes e bases da educação nacional. Além disso, foram abordadas a necessidade de criação de novas leis e decretos que possibilitem a oferta do FIES para alunos da modalidade a distância; condicionamento e oferta de um maior percentual de semipresencialidade em cursos lato-sensu; autonomia nos processos avaliativos e regulatórios de credenciamento, bem como, um fluxo regulatório diferenciado para instituições com experiência em EaD. Por fim, propuseram indicações referentes à urgência na regulação e na expansão da modalidade a distância com qualidade.

Entretanto, dentre todas as proposições sugeridas, algumas não foram atendidas na elaboração do Parecer 564/2015. Conforme destacado pela ABED (2016, p.2-3) em carta enviada ao Ministro da Educação, ficaram pendentes os ajustes referentes à: 
a) autorização e regulamentação do uso de Bibliotecas Digitais; b) autorização e regulamentação para expansão de polos das IES que tenham IGC contínuo igual ou superior a 4 , sendo que a IES poderá expandir o número de polos a cada dois anos, sem necessitar de visita prévia para sua ativação. As visitas e avaliações referentes a esses polos ocorrerão quando do reconhecimento dos cursos oferecidos e/ou no recredenciamento da IES, o que acontecer primeiro; c) permissão para que sejam constituídas IES para oferta exclusiva de cursos na modalidade a distância; d) definição da modalidade dos cursos considerando o maior percentual da modalidade de oferta das atividades de ensino e de aprendizagem; e) permissão para que as IES sejam efetivamente autônomas, como definido na Lei de Diretrizes e Bases da Educação Nacional - LDB 9394/96, para descrever seus projetos, metodologias e modelos didático-pedagógicos para o ensino mediado por tecnologia de informação e comunicação, determinados nos seus documentos institucionais: Projeto de Desenvolvimento Institucional - PDI, Projeto Pedagógico Institucional - PPI e Projeto Pedagógico de Curso - PPC, de modo a promover, com seu corpo administrativo, docente, tutores e discentes, uma educação de qualidade e inclusiva, independente da modalidade de ensino; f) necessidade de uma profunda revisão dos Referenciais de Qualidade para Educação Superior a Distância (2007), de modo a contemplar diversos modelos didático-pedagógicos, que não necessariamente demandem tutoria presencial, além de diferentes metodologias recentemente incorporadas ao cotidiano da sociedade, assim como a necessidade de revisão da Portaria Normativa no $40 *$, de 2007 , g) instituir o e-MEC, sistema eletrônico de fluxo de trabalho e gerenciamento de informações relativas aos processos de regulação, avaliação e supervisão da educação superior no sistema federal de educação, e o cadastro e-MEC de instituições e cursos superiores e consolida disposições sobre indicadores de qualidade, banco de avaliadores (Bases) e o Exame Nacional de Desempenho de Estudantes (ENADE) e outras disposições.

Apesar dos avanços propostos pelo marco regulatório, as novas diretrizes não abordam tais questões. Logo, na redação da Resolução no 1 , de 11 de março de 2016 percebeu-se que muitas das sugestões da ABED estão presentes, no entanto, ainda não configuram avanços significativos conforme a citação acima.

\section{CONCLUSÕES}

Após a realização deste estudo, apresentam-se algumas considerações sobre o tema de investigação proposto, o qual objetivou, ao longo de seu desenvolvimento, a reflexão a respeito do contexto da Educação a Distância, sua relação com a legislação e documentos vigentes, incluindo as novas Diretrizes e Normas Nacionais para a oferta de Programas e Cursos de Educação Superior na Modalidade a Distância.

O estudo minucioso do contexto educacional do Ensino Superior tem provocado grandes impactos nas validações de pesquisas nesta área, especialmente no que se refere à Educação a Distância, visto que os atos normativos, súmulas, os pareceres e as resoluções, constituem a essência fundamental da identidade desta modalidade de ensino. Dessa forma, faz-se necessário para tanto, muita cautela e vigilância na compreensão destes documentos a fim de fundamentar e legitimar à educação aberta e flexível. 
Os documentos norteadores possibilitam a definição dos princípios, diretrizes e critérios para as instituições que oferecem cursos nesta modalidade, a organização de sistemas de Educação a Distância no país e a garantia de um rigoroso padrão de qualidade, de modo a garantir além de sua efetivação. Essas proposições, também foram apontadas como sugestões para os avanços e as mudanças do marco regulatório e refletiram na aprovação do Parecer 564/2015 e, posterior, Resolução $\mathrm{n}^{\circ} 1$, de 11 de março de 2016.

Neste sentido, o debate virtual sobre o Novo Marco Regulatório para a EaD (2015) apontou as novas diretrizes para a oferta de cursos e programas. A partir desta audiência interativa, identificou-se a discussão em torno dos "Referenciais de qualidade para EaD" e constatou-se maior enfoque para as questões relacionadas aos aspectos pedagógicos, de recursos humanos e de infraestrutura.

Espera-se que a investigação ora proposta, possa facilitar o entendimento dos documentos aqui analisados e das melhorias apontadas, legitimando e consolidando os avanços desta modalidade, contribuindo para a expansão e alcance da equidade da educação.

\section{REFERÊNCIAS BIBLIOGRÁFICAS}

ABED. Carta da ABED enviada ao Ministro da Educação. Disponível em: <http://www.abed.org.br/arquivos/Carta_ABED_EAD_Ministro_Educacao_2016.pdf >. Acesso em: 12 jul. 2016.

BRASIL. CE - Comissão de Educação - 15/10/2015. Audiência pública interativa para debater o Marco Regulatório da Educação a Distância. Disponível em: <https://www.youtube.com/watch?v=ZFBL5tOFZEU\&feature=youtu.be>. Acesso em: 15 jul. 2016.

BRASIL. Decreto $\mathbf{n}^{0}$ 5.622, de 19 de dezembro de 2005. Disponível em: <http://portal.mec.gov.br/seed/arquivos/pdf/dec_5622.pdf.> Acesso em: 15 jul. 2016.

BRASIL. Lei $\mathbf{n}^{0}$ 13.005, de 25 de junho de 2014. Disponível em: <http://www.planalto.gov.br/ccivil_03/_ato2011-2014/2014/lei/113005.htm>. Acesso em: 20 jul. 2016.

BRASIL. Parecer CNE/CES No 564/2015. Disponível em: <http://www.abed.org.br/arquivos/parecer_cne_ces_564_15.pdf >. Acesso em: 20 jul. 2016.

BRASIL/MEC/SEED. Referenciais de Qualidade para a Educação Superior a Distância. $2007 . \quad$ Disponível em: <http://portal.mec.gov.br/seed/arquivos/pdf/legislacao/refead1.pdf.> Acesso em: 18 ago. 2016.

BRASIL. Resolução $\mathbf{n}^{\mathbf{0}} \mathbf{1}$, de 11 de março de 2016. Disponível em: $<$ http://portal.mec.gov.br/index.php?option=com_docman\&view=download\&alias=355 
41-res-cne-ces-001-14032016-pdf\&category_slug=marco-2016-pdf\&Itemid=30192> . Acesso em: 20 ago. 2016.

PRODANOV, C. C., FREITAS, E. C. Metodologia do trabalho científico [recurso eletrônico]: métodos e técnicas da pesquisa e do trabalho acadêmico - 2. ed. - Novo Hamburgo: Feevale, 2013.

SÁ-SILVA, J. R.; ALMEIDA, C. D. de; GUINDANI, J. F. Pesquisa documental: pistas teóricas e metodológicas. Revista Brasileira de História \& Ciências Sociais, Ano I, n. I, Jul. 2009. Disponível

em:<http://www.unisc.br/portal/upload/com_arquivo/pesquisa_documental_pistas_teori cas_e_metodologicas.pdf> Acesso em: 20 ago. 2016. 